University of Nebraska - Lincoln

DigitalCommons@University of Nebraska - Lincoln

\title{
Effectiveness of cattle operated bump gates and exclusion fences in preventing ungulate multi-host sanitary interaction
}

\author{
J.A. A. Barasona \\ IREC Instituto de Investigacion en Recursos Cinegeticos, JoseAngel.Barasona@uclm.es \\ K. C. VerCauteren \\ USDA-APHIS-Wildlife Services, kurt.c.vercauteren@usda.gov
}

N. Saklou

USDA/APHIS/WS

C. Gortazar

IREC Instituto de Investigacion en Recursos Cinegeticos

J. Vicente

IREC Instituto de Investigacion en Recursos Cinegeticos

Follow this and additional works at: https://digitalcommons.unl.edu/icwdm_usdanwrc

Barasona, J.A. A.; VerCauteren, K. C.; Saklou, N.; Gortazar, C.; and Vicente, J., "Effectiveness of cattle operated bump gates and exclusion fences in preventing ungulate multi-host sanitary interaction" (2013). USDA Wildlife Services - Staff Publications. 1223.

https://digitalcommons.unl.edu/icwdm_usdanwrc/1223

This Article is brought to you for free and open access by the U.S. Department of Agriculture: Animal and Plant Health Inspection Service at DigitalCommons@University of Nebraska - Lincoln. It has been accepted for inclusion in USDA Wildlife Services - Staff Publications by an authorized administrator of DigitalCommons@University of Nebraska - Lincoln. 


\title{
Effectiveness of cattle operated bump gates and exclusion fences in preventing ungulate multi-host sanitary interaction
}

\author{
J.A. Barasona ${ }^{\mathrm{a}, *}$, K.C. VerCauteren $^{\mathrm{b}}$, N. Saklou $^{\mathrm{b}}$, C. Gortazar $^{\mathrm{a}}$, J. Vicente ${ }^{\mathrm{a}}$ \\ a IREC Instituto de Investigacion en Recursos Cinegeticos (CSIC-UCLM-JCCM), Ronda de Toledo s/n, 13071 Ciudad Real, Spain \\ b USDA/APHIS/Wildlife Services, National Wildlife Research Center, Fort Collins, CO 80521, USA
}

\section{A R T I C L E I N F O}

\section{Article history:}

Received 9 January 2013

Received in revised form 19 March 2013

Accepted 20 March 2013

\section{Keywords:}

Cattle operated gates

Exclusion fences

Tuberculosis

Livestock/wild ungulates interface

Water points

\begin{abstract}
A B S T R A C T
Tuberculosis (TB) is endemic in Eurasian wild boar (Sus scrofa) and red deer (Cervus elaphus) in south central Spain, where evidence suggests transmission to domestic cattle. Known risk factors for $\mathrm{TB}$ at the interface between livestock and wild ungulate species include density and spatial overlap, particularly around waterholes during summer. We evaluated the effectiveness of selective exclusion measures for reducing direct and indirect interaction between extensive beef cattle and wild ungulates at waterholes as an alternative for the integrated control of TB. We first monitored 6 water points (WP) with infrared-triggered cameras at a TB positive cattle farm to quantify interactions. We then assigned $3 \mathrm{WP}$ to be "cattle-only" and 3 to be "wildlife-only". Cattle-only WP were surrounded with a wildlifeproof fence ( $2.5 \mathrm{~m}$ high) and an original design of cattle-specific gate. Wildlife-only WP were surrounded by a fence that wild ungulates could breach but cattle could not $(1.2 \mathrm{~m}$ high). Red deer, roe deer (Capreolus capreolus) and wild boar easily jumped or undercrossed this fence. Wildlife-only fences were $100 \%$ effective in preventing cattle access to WP and did not impede wildlife use. Many cows learned to operate the cattle-specific gate quickly and others followed and learned from them. Within 2 weeks, around $70 \%$ of cows actively entered and exited through the cattle-specific gate. We demonstrate how simple, lowcost fencing strategies can serve as biosecurity measures to substantially reduce direct and indirect contact between cattle and wild ungulates, serving to reduce the potential for TB transmission. Our designs can be used in the context of integral plans to mitigate disease transmission between cattle and wildlife, and have potential for protecting or segregating the use of a variety of resources in different contexts.
\end{abstract}

(c) 2013 Elsevier B.V. All rights reserved.

\section{Introduction}

Sharing diseases between wildlife and livestock has been favoured in many regions for different reasons: increase in wildlife densities, intensive management, changes in livestock breeding systems, reduction of human presence in pastures (Corner, 2006; Gortazar et al., 2007). In Mediterranean extensive farming habitats from southern Iberia, there is a tendency of private livestock farms

\footnotetext{
* Corresponding author. Tel.: +34 926295450; fax: +34 926295451.

E-mail addresses: JoseAngel.Barasona@uclm.es, joseangel_barasona@hotmail.com (J.A. Barasona).
}

to become hunting estates (Delibes-Mateos et al., 2009), gathering wild and domestic ungulates in the same geographical area. Interactions between wildlife and livestock create significant risks for disease transmission (Phillips et al., 2003; Kuiken et al., 2005), which increase when animals congregate and share resources (Miller et al., 2003; Wobeser, 2006). For instance, Tuberculosis (TB) is endemic in Eurasian wild boar (Sus scrofa) and red deer (Cervus elaphus) in south-central Spain (Vicente et al., 2005; Naranjo et al., 2008), and evidence suggests transmission to domestic cattle (Aranaz et al., 2004; Gortazar et al., 2007, 2011a). Under dry Mediterranean conditions, known risk factors for TB (and other diseases) in the livestock/wild ungulates interface include spatial aggregation around waterholes 
during summer (Vicente et al., 2007). Previous studies remark the possibility of indirect TB transmission between wildlife and cattle (Palmer et al., 2001; Phillips et al., 2003; VerCauteren et al., 2008; Walter et al., 2012). For example in UK, cattle could be infected by contact with farm buildings (feed stores and cattle sheds) and grazing on grass contaminated by badger urine, faeces, sputum or wound exudates (e.g. Hutchings and Harris, 1999; Garnett et al., 2002; Delahay et al., 2005). Usually, wildlife and livestock share the interface (space) at different times, so the disease interface between wildlife and livestock usually is indirect contact (Palmer et al., 2001, 2004). Though highly variable, Mycobacterium bovis bacteria persist in the environment for months (Duffield and Young, 1985; Fine et al., 2011), long enough to represent a risk of exposure for wildlife and cattle. Moreover, direct transmission between wildlife and cattle can occur when wildlife visit farms (Paterson et al., 1995; Böhm et al., 2009; Tolhurst et al., 2009).

Integral approaches to control disease at the wildlife/livestock interface require mitigation of contact to reduce disease transmission between wildlife and cattle, including adequate biosecurity, husbandry measures and pasture management (Hutchings and Harris, 1997; Judge et al., 2011). Ideally, we must improve biosecurity by using reliable long-term nonlethal barriers in problematic areas, especially in certain spatially limited risk situations (Seward et al., 2007; Judge et al., 2011). Preventing aggregation and subsequent contact between domestic and wild animals at water points (WP) may be valuable for disease transmission control in Southern Iberia. One possibility is to devote WP selectively to wildlife or livestock, requiring appropriate livestock- or wildlife-proof barriers, respectively. Since cattle have less ability to pass through fences than wild ungulates (Berentsen et al., 2007), this strategy may also require cattle-only gates. Several reports have examined the efficacy of a variety of psychological, physical and biological barrier alternatives to traditional methods to evaluate their potential to be used for excluding or containing wild ungulates. Frightening devices (Seward et al., 2007), laser lights (VerCauteren et al., 2006a), propane gas exploders (Gilsdorf et al., 2004), livestock protection dogs (VerCauteren et al., 2008; Gehring et al., 2011), human-used bump gates (VerCauteren et al., 2009), electrified enclosures (Karhu and Anderson, 2006; Reidy et al., 2008) and fencing (VerCauteren et al., 2006b; Lavelle et al., 2011; Phillips et al., 2012) have all been evaluated and have varying efficacy in deterring wild ungulates from cattle resources. A fence design has been tested to successfully exclude elk without impeding other wildlife, including smaller ungulates (VerCauteren et al., 2007), which is based on the fact that different body size impacts the ability to breach. Nonetheless, no research has examined the ability of selective cattle operated-gates.

Our general aim was to provide scientific basis on biosecurity measures to protect livestock economies from threats represented by wildlife reservoirs under Mediterranean dry conditions in south central Spain. We tested the efficacy of livestock- and wildlife-proof fences, respectively, together with a novel selective cattle-operated gate, in order to segregate the use of WP between cattle and wild ungulates, and to evaluate the potential to reduce TB transmission at the wildlife/livestock interface.

\section{Material and methods}

\subsection{The study area}

Extensive livestock farming in the south-western Iberian Peninsula is practiced in typical agroforestry systems called "dehesas" (savannah-like habitats, 3.1 million ha in Spain; Moreno and Pulido, 2008) and includes cattle, sheep and pigs. Dehesas are pastures that mainly include oak trees (Quercus spp.) and are used for grazing. They are commonly in the proximity of Mediterranean forests/scrublands. Different uses, namely agriculture, livestock husbandry, forestry and hunting activities all occur in dehesas. The woody areas of such properties are usually devoted to hunting, which has often become the predominant source of "income" (Olea and San Miguel-Ayanz, 2006). This results in an interspersed distribution of land uses. We conducted our trials on a livestock breeding estate in the Southern province of Ciudad Real, Castilla-La Mancha region, south central Spain (see Fig. 1). The study area is within a TB-endemic zone and contains high densities of wild ungulates which harbour the highest prevalence rates of $M$. bovis reported in the literature (Vicente et al., 2005; Gortazar et al., 2006). Thus there is a very high risk of outbreaks in farms (Rodriguez-Prieto et al., 2012).

The average stocking $( \pm S D)$ rate in the study area (Almodovar Shire) was $138 \pm 129$ beef cows per farm. Our study farm size is 499 ha. Cattle ranching and hunting both occurred on the property. The land's perimeter was fenced and fence divided it into two areas: north (65 cows) and south (50 cows). Water is present in water holes (3 in north and 2 in south) and one elevated trough (in South). Water is also available in seasonal streams during the fall. The south part of the study area is composed by Mediterranean forest bordering the dehesa, while the north part is composed of typical dehesa habitat (Fig. 1). The big game species present included wild ungulates: red deer, roe deer (Capreolus capreolus) and wild boar. Cattle in the south roamed and foraged in the dehesa and forest. The cattle were never indoors. Annual rainfall is variable in the study region (ranging from 300 to $700 \mathrm{~mm}$ ) and the climate is Mediterranean with a continental influence. The wet season typically starts in September-October and contributes most of the annual rainfall. The dry season, from June thru August, is when food and water resources become limited for livestock and wild ungulates (Bugalho and Milne, 2003).

\subsection{Study design, fences and cattle operated-gates}

We implemented biosecurity measures to promote selective spatial segregation between cattle and wild ungulates in all WP, which includes 5 WP (ranging from 45 to 90 m perimeter) and 1 manufactured watering trough (which is an approximately $1 \mathrm{~m}$ elevated longitudinal pool). WP were divided into two fencing groups; $3 \mathrm{WP}$ to be "cattle-only", which we hypothesize would allow cattle to enter while preventing access to wild ungulates, and 3 to 


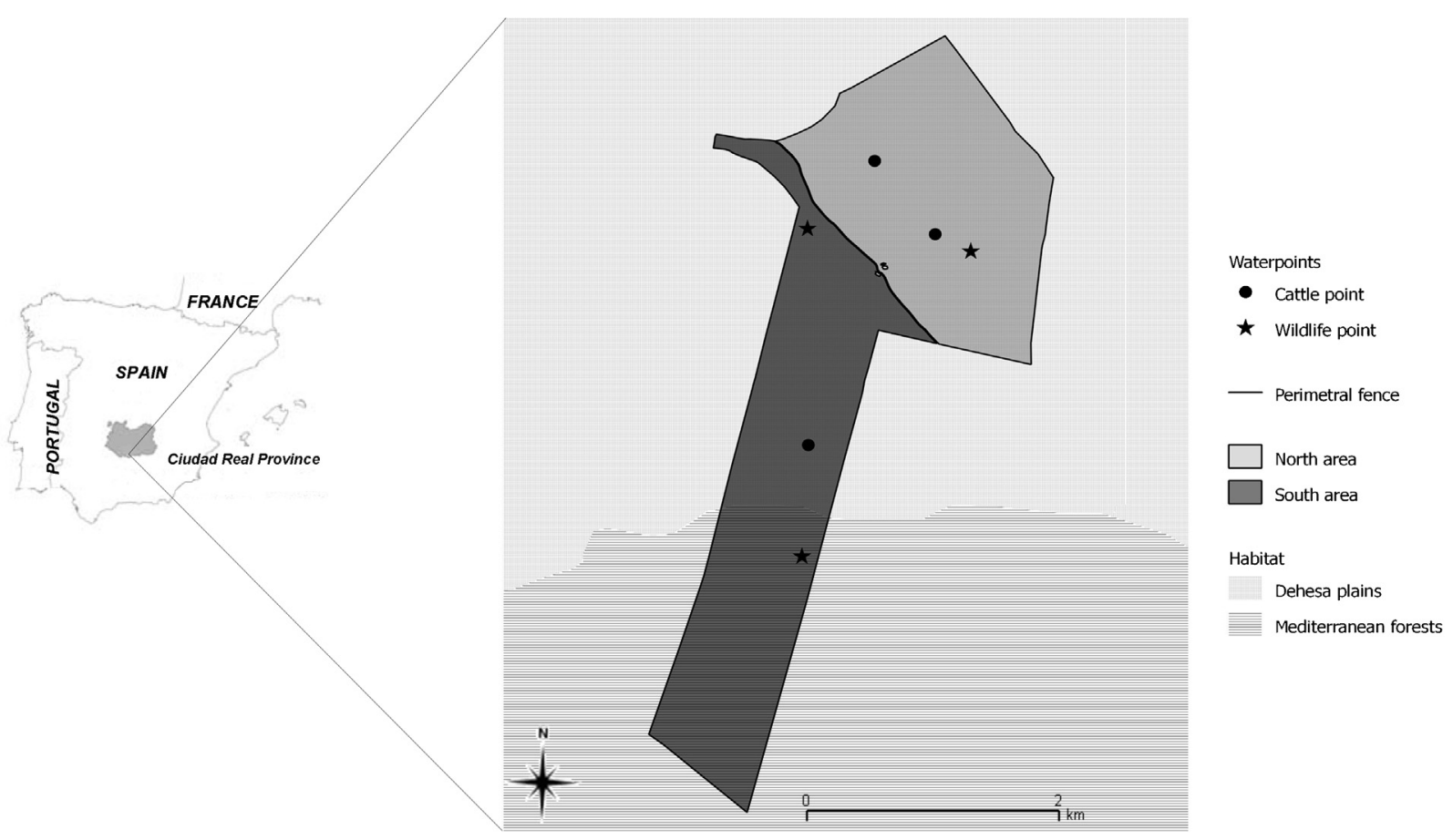

Fig. 1. Map of study area in of Ciudad Real province. Habitat and water point distribution at the farm.

be "wildlife-only". Cattle-only WP were surrounded with a wildlife-proof fence $(2.5 \mathrm{~m}$ high, stapled to the ground in order to prevent wild boar from passing under) and our cattle-specific gate (see Fig. 2). Wildlife-only WP were surrounded by a fence ( $1.2 \mathrm{~m}$ high) that cattle could not pass but deer and wild boar, respectively, easily jumped (Vercauteren et al., 2010) or undercrossed, due to ground level passes (not stapled area suitable for wild boar) and roe deer-selective openings (which consisted of an $18 \mathrm{~cm}$ width, $60 \mathrm{~cm}$ height frame) (Fig. 2).

The cattle-operated gate is installed in a frame gate made of round steel pipe with mesh infill. The gate has a simple mechanism operated by mechanical power and gravity that can be activated by cattle, requiring just basic skills and tools to install, and little maintenance. This mechanism weighs around $16 \mathrm{~kg}$. Bump gates were originally designed for use by vehicles, bumping an arm situated in the gate with the vehicle's bumper while the driver stays within the vehicle (Bump Gates Australia, Queensland, Australia). Cattle are supposed to be unable to open these bump gates. We designed our novel bump gate such that it could be activated by cattle. There is an arm on either side of the bump gate and it can open in both directions. To open the gate pressure must be applied to the arm, which releases a spring-loaded lockpin that provides momentum for the gate to open. When the gate opens at a given angle, it strikes a delay catch, which holds it open while the animal passes through. After a few seconds, the delay catch releases the gate and the gate closes behind the animal. The gateway should be installed on terrain with no slope. The bump gate is always closed (the lockpin locked) except during the time that opening is activated and a few seconds of delay thereafter. We used a $3.5 \mathrm{~m}$ width gate, sited to the most level ground possible, and adjusted the cable settings so that cattle bumping the arm could easily trigger it to open. Among the animals present in our study site, cattle can push harder than any other to bump the gate, and our prediction was that lighter animals (deer) could not trigger the opening. The arm is $1.40 \mathrm{~m}$ from the ground, impeding wild boar and roe deer access.

Phase 1 (Control): The first phase of the study consisted of observing and quantifying with infrared-triggered cameras (NightTrakker NT50 8.0 MP, Uway, Norcross, Georgia, USA) (at least 2 per WP) the activity by cattle and wildlife in all WP during 1 month prior to implementing biosecurity and segregation measures, so every WP was available for both cattle and wild ungulates.

Phase 2 (Progressive adaptation to fences and selective gates): WP were fenced as previously indicated (it took an average of 2 days 2 workers to install fences for one WP, Fig. 1). In the north area, two WP were fenced to allow for cattle-only use, whereas one WP was devoted to wildlife-only use. The two WP available in the South area, close to the forest, were fenced to permit wild ungulate-only access and the water trough was devoted to cattle-only use. Cattle were progressively introduced to bump gates. (i) First, gates remained open all the time for one week. We modified the opening device to enable most cattle to open the gates with active behaviour (Grandin, 1980). Cattle have cutaneous sensitivity under the neck and behind the ears, areas they find difficult to access (Moran, 1993). They frequently scratch themselves on posts and brushes for cleansing, to establish social structure in the herd and to remove insects, parasites and dead skin (Simonsen, 1979; Moran, 1993). Scratching devices like brushes have been provided to 

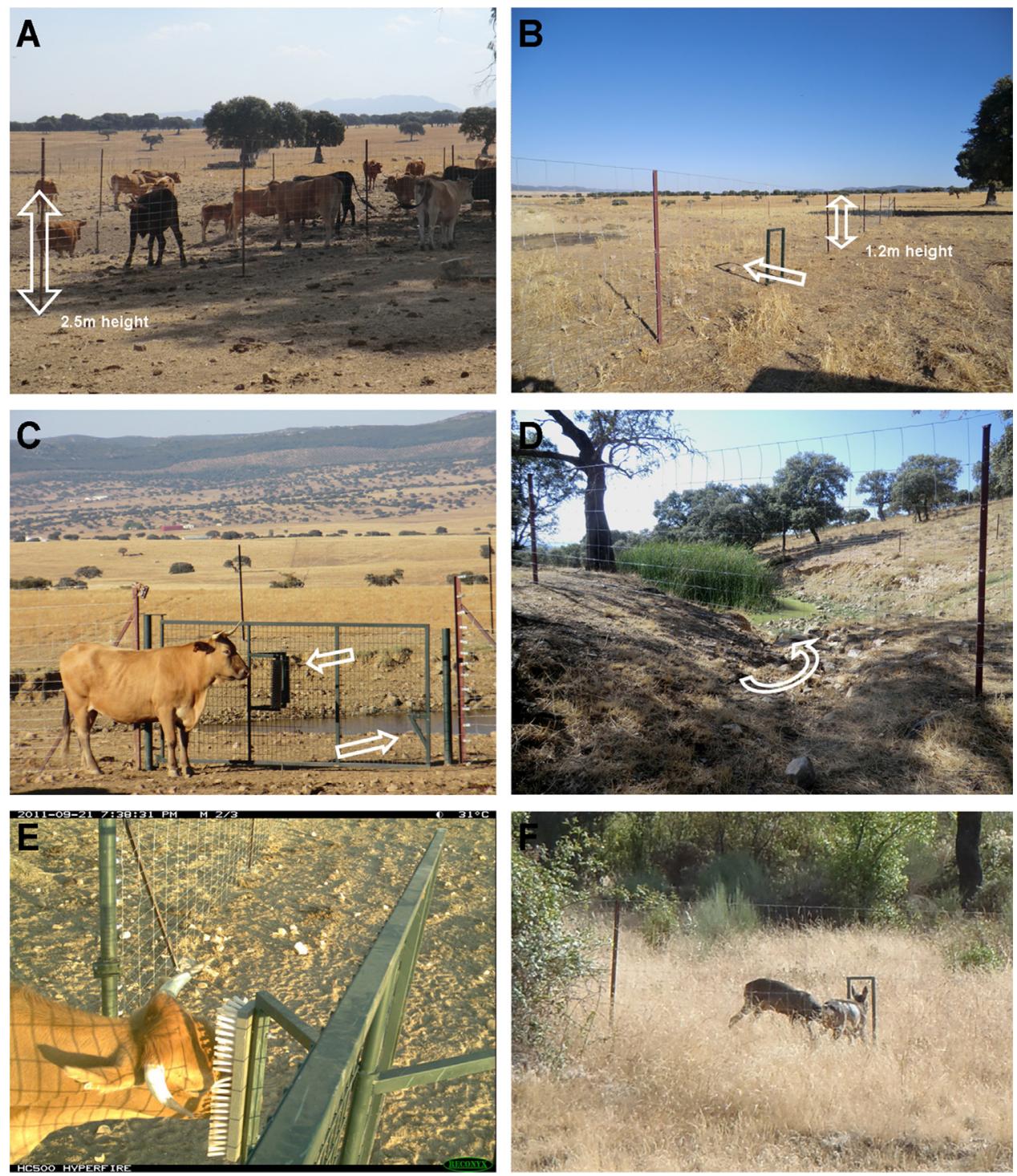

Fig. 2. (A) Wild ungulate proof fence in "cattle waterhole", (B) cattle proof fence in "wildlife waterhole", suitable for deer jumping, (C) cattle-only gate, (D) ground level pass, suitable for wild boar and roe deer, (E) brush cattle arm, (F) roe deer (and potentially piglet) selective opening (18 cm width, $60 \mathrm{~cm}$ height frame) in cattle-proof fence.

cattle to enable them to perform such important natural behaviour (e.g. http://www.delaval.es/en/-/ProductInformation1/Animal-comfort-care/Products/Bodycare/Cow-brushes/DeLaval-swinging-cow-brush), and even to apply anti-parasitic treatment whilst brushing (with the incorporation of small spigot valves). At this phase, we installed a $60 \mathrm{~cm}$ long brush, made of hard hair $(10 \mathrm{~cm}$ long), in the arm of the gates so animals could identify and use the scratching site before next step. (ii) The following week, the gates were left loose, so cattle would easily open them while brushing. We used operant conditioning (associative learning) to modify the behaviour of the cattle (Lee et al., 2009). Cattle would associate brushing with the consequence, opening of the gate and gaining access to the interior of the enclosure where water is.
Phase 3 (Gates latched): Finally, the spring-loaded lockpins were activated in cattle-only fences, so the gate remained closed, and only opened when the arm (with the brush) was bumped. We observed the evolution of cattle behaviour for 4 weeks after the gates were latched.

\subsection{Data collection and analysis}

We first aimed to describe and quantify the livestock/wildlife interaction at the interface of the water sources of the farm (Phase 1). We used camera trapping during summer before implementing biosecurity measures and selective spatial segregation of livestock and wild ungulates of WP during the months of June-July 2011. Camera traps were set near water sources. We fixed cameras to posts or tree trunks when available, focusing on 
the perimeter of the WP. Several cameras $(n=16)$ were set at WP in order to capture as much area as possible. We also measured change in behaviour (success in gaining access to the enclosures) in Phase 3 using cameras focussed on the gates. Cameras were set to take 3 pictures following each trigger and the selected period of time before cameras re-activated was the minimum, 5 s, 24 h/day. The date and time of each exposure was recorded by the cameras and images were stored on SD cards. The pictures were then downloaded and stored as JPEG files, visualized and interpreted. Information was processed in Excel files (Microsoft Excel, version 2007; Microsoft Coorporation), for each individual picture the following variables were recorded: camera unit identifier (site), date $(\mathrm{dd} / \mathrm{mm} / \mathrm{yy})$, time (hours, minutes and seconds), number of individuals of each species and their main behaviours (rooting, foraging, drinking, licking, "nose-to-nose" contacts). To assess the use of bump activated gates we also recorded the passes to enter the enclosure, and for each pass, the number of cows that passively entered along with cows that had activated the bump-gate.

We describe our findings in terms of daily presence (\% of days with detected presence) with $95 \% \mathrm{CI}$. In order to compare daily presence figures for a given species before and after selective fencing measures were implemented, we used Fisher's exact tests (STATISTICA 9.0 software, version 7.1., StatSoft, Inc, www.statsoft.com). To explore the efficacy of selective gate implementation in terms of expected TB herd rate decrease (based on skin tests), we compared the trend (by using Chi ${ }^{2}$ test, IBM SPSS 19.0 software, IBM Corporation, Somers, NY, USA) against the 9 cattle farms ( $n=1873$ cows) situated in a $20 \mathrm{~km}$ radius around the study farm from campaign 2008 to 2012 (before and after we implemented selective fencing measures). Data on skin tests were provided by the sanitary authorities.

\section{Results}

\subsection{Pre-experiment activity of wildlife at water points}

The involved species and daily presence (\% of days with presence) per WP during Phase 1 (before biosecurity measures were implemented) are shown in Table 1. Both wild ungulates and livestock were observed in 3 out of 5 waterholes, and no wild ungulates were detected at the water trough. Three WP were not visited by wild ungulates, especially those located in the north area. Interestingly, cattle frequently used the nearest WP to the forest, which was the one most used by wildlife. In terms of daily presence (\%) per WP, the most frequent wild ungulates were red deer (24\%), followed by roe deer (18\%) and wild boar (9\%). Most of WP-days were visited by livestock (66\%). We reported presence of wildlife and livestock the same day at $17 \%$ of WP by day, of which $33 \%$ were cattle-red deer, $21 \%$ cattleroe deer, and $17 \%$ were cattle-wild boar. Although domestic and wild ungulates shared the same WP, we did not document both in the same picture. Other wild mammals detected at WP included red fox (Vulpes vulpes) (11\%) and Iberian hare (Lepus granatensis) (4\%). Wild ungulates and cows partitioned WP use temporally, especially wild boar.

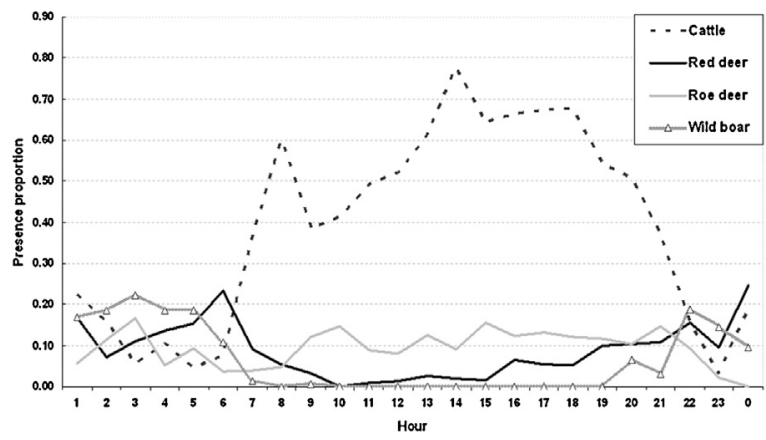

Fig. 3. Ungulate daily activity patterns. Cattle-wild ungulate presence proportion (visits of each ungulate species/total visits by hour) to all study period by hour of the day.

Wild ungulates used WP more frequently during nocturnal hours (see Fig. 3).

\subsection{Cattle operated gates: learning process}

Following installation of brushes on arms of cattleoperated gates (Phase 2), we observed frequent use of them by cattle during the first week (34.5\% active passes, $n=204$ ). During this phase, most of the active passes into the cattle-only enclosures were individual (59.1\%). Once the gates were locked (Phase 3), from day 16 onwards, the proportion of active passes into the enclosures (cattle bumped the gate) markedly increased, so that by day 16 over $70 \%$ of the reported passes were active, and this proportion was maintained constant over the remaining study period (Fig. 4). Passive passes consisted of cows and calves (9.5\%) that entered the enclosure with another individual which actively triggered the gate to open. This means that, although individual identification and tracking of all individuals was not possible, all cows entered and gained access to water, most of them actively triggering the gate opening system. Cameras detected no wildlife activity at gates, and therefore no successful entering was recorded in cattle-only enclosures (see below), although deer and their tracks (faecal pellets, footprints) were commonly detected around the south cattle-only enclosure.

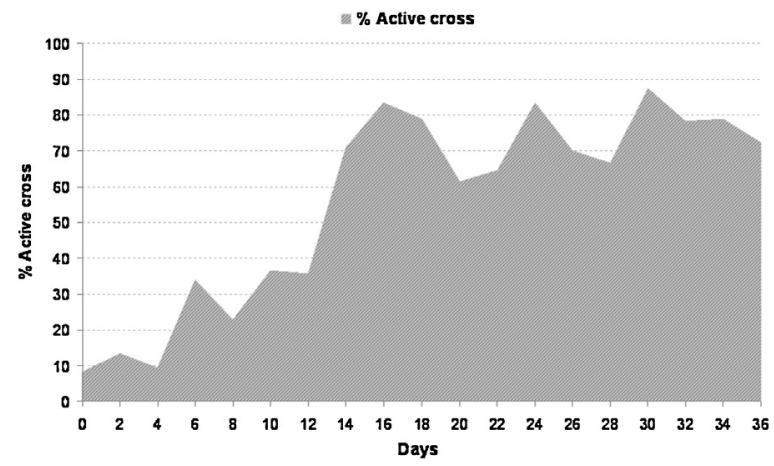

Fig. 4. Trend in the proportion of active passes (cattle trigger gate to open) against passive passes (cattle that passively entered once another cow previously and actively had bumped and opened the gate) into the cattleonly enclosure WP during Phase 3. 
Table 1

The involved species and daily presence (\% of days with presence) per WP during Phase 1 and 3 (Phase 1/Phase 3).

\begin{tabular}{|c|c|c|c|c|c|c|c|}
\hline Area & Water point & Type & Cow & Red deer & Roe deer & Wild boar & Red fox \\
\hline \multirow[t]{6}{*}{ North } & \multirow[t]{2}{*}{ Waterhole } & \multirow[t]{2}{*}{ Wildlife } & $85 \%$ & $0 \%$ & $0 \%$ & $3 \%$ & $27 \%$ \\
\hline & & & $\mathbf{0} \%$ & $\mathbf{0} \%$ & $0 \%$ & $7 \%$ & $19 \%$ \\
\hline & \multirow[t]{2}{*}{ Waterhole } & \multirow[t]{2}{*}{ Cattle } & $73 \%$ & $0 \%$ & $0 \%$ & $0 \%$ & $5 \%$ \\
\hline & & & $75 \%$ & $\mathbf{0} \%$ & $\mathbf{0} \%$ & $\mathbf{0} \%$ & $17 \%$ \\
\hline & \multirow[t]{2}{*}{ Waterhole } & \multirow[t]{2}{*}{ Cattle } & $100 \%$ & $0 \%$ & $0 \%$ & $0 \%$ & $14 \%$ \\
\hline & & & $\mathbf{8 0} \%$ & $\mathbf{0} \%$ & $\mathbf{0} \%$ & $0 \%$ & $16 \%$ \\
\hline \multirow[t]{6}{*}{ South } & \multirow[t]{2}{*}{ Waterhole } & \multirow[t]{2}{*}{ Wildlife } & $29 \%$ & $74 \%$ & $61 \%$ & $18 \%$ & $8 \%$ \\
\hline & & & $0 \%$ & $43 \%$ & $65 \%$ & $22 \%$ & $16 \%$ \\
\hline & \multirow[t]{2}{*}{ Waterhole } & \multirow[t]{2}{*}{ Wildlife } & $41 \%$ & $14 \%$ & $0 \%$ & $14 \%$ & $7 \%$ \\
\hline & & & $\mathbf{0 \%}$ & $20 \%$ & $\mathbf{0} \%$ & $32 \%$ & $\mathbf{0} \%$ \\
\hline & \multirow[t]{2}{*}{ Elevated trough } & \multirow[t]{2}{*}{ Cattle } & $75 \%$ & $0 \%$ & $0 \%$ & $0 \%$ & $6 \%$ \\
\hline & & & $89 \%$ & $\mathbf{0} \%$ & $\mathbf{0} \%$ & $\mathbf{0} \%$ & $\mathbf{0} \%$ \\
\hline
\end{tabular}

\subsection{Segregation between cattle and wildlife}

WP in the north part of the farm and the water trough in the south part, where no wildlife entered, were fenced in order to allow passage of cattle. In Phase 3, the wildlife-only fences were $100 \%$ effective in preventing cattle entry into wildlife-only WP (Fig. 5a) and this effect was statistically significant (Fisher's exact tests, $p<0.001$ ). It is remarkable that in the WP from the north area devoted to wildlife, cattle were the most present animal in Phase 1 (Fig. 5b). No wildlife were detected by trap cameras trying to enter thru the cattle-only gates, and therefore, we could not test whether cattle-only enclosures decreased wild ungulate visits. No signs of wild ungulates aversion towards WP fenced to prevent cattle access was evidenced since, even in short term, there was no reduction of wild ungulate visits to those WP intended for wildlife (Fig. 5b; Fisher's exact tests, $p>0.05$ for wild boar, red and roe deer). In fact, an increased trend for wild boar was observed.

Finally, whereas TB incidence based in skin tests in the cattle farms situated in a $20 \mathrm{~km}$ radio around the study farm kept constant at around 3\% ( $n=1873$ cows in 9 control farms from campaign 2008 to 2012), the incidence in our study farm after selective gates were implemented significantly decreased from $7.5 \%$ to $1.6 \%\left(C h i^{2}\right.$ test, $\left.p<0.05\right)$ after selective gates were implemented. Temporal trends and tested animals are included in Fig. 6.

\section{Discussion}

Our experiment showed (i) that most cattle learned to use selective cattle-operated gates after a relatively short period of adaptation and (ii) that effective segregation of wildlife and livestock at WP under dry Mediterranean conditions can be achieved by complementing adequate fences with selective passes and cattle-operated gates. Our design, therefore, has potential for reducing contacts and disease transmission at the livestock/wildlife interface.

\subsection{Cattle-operated gates and the learning process}

In this study, cattle demonstrated the ability to quickly adapt to a new element (fences provided with selective gates) that progressively was introduced in proximity to a resource that is used by them daily. An increased percentage of cows crossing specific gates actively was observed during the study period, most of them operating the gates within a two-week period. Although no individual behaviour was annotated, our observations suggest that some individuals learned how to trigger the gate and access the WP more quickly and easily than others. Cattle are highly hierarchical (Phillips, 2002), and therefore the standing of high hierarchical level individuals by the gate may deter subordinate individuals (Simonsen, 1979) from using the gate for a while, and they stand or roam around waiting for their turn. We therefore recommend installing two gates in opposite positions in the enclosure to improve the entry.

From a practical point of view, this is a cost-effective automatic non-sophisticated device, which does not need electricity or an external power source; it operates by mechanical power to unlock and open, and gravity to close and lock. The cost of the cow-operated device, less than $200 €$, together with that of the gate (which may be a pre-existent gate) is also an advantage, compared with electric-powered devices, hydraulic units, etc., (which are much more expensive and also more costly to repair and maintain). Therefore, it is affordable for farmers or sanitary authorities to change several gates into cattlespecific gates. The highest expenses were associated with the cattle-only fences ( $12 €$ per metre, $275 \mathrm{~m}$ of perimeter) followed by the wildlife-only fences $(7.5 € / \mathrm{m}, 325 \mathrm{~m}$ of perimeter), as a result, the costs of the facilities we implemented in this study averaged $1010 €$ per WP. Whereas TB incidence based on skin tests in nearby cattle farms farm kept constant, the incidence in our study farm significantly decreased from $7.5 \%$ to $1.6 \%$ just after applying segregating wildlife and livestock around waterholes (next testing occurred early in the year 2012). More evidence is still needed since our study design was not properly experimental, and replicas are needed. Nonetheless, our study farm reduced their losses due to reduced number of TB positive animals, and therefore the investment may result beneficial in a short-term period. As indicative, the losses by Spanish beef farmers after obligatory slaughtering averages of TB positive animals can be measured in terms of the compensation obtained by insurance companies to cover such losses, which ranges between 300 and $900 €$ in 2012 (for a 2-5 years old cattle, depending on the genetics value). In addition we have to add the 


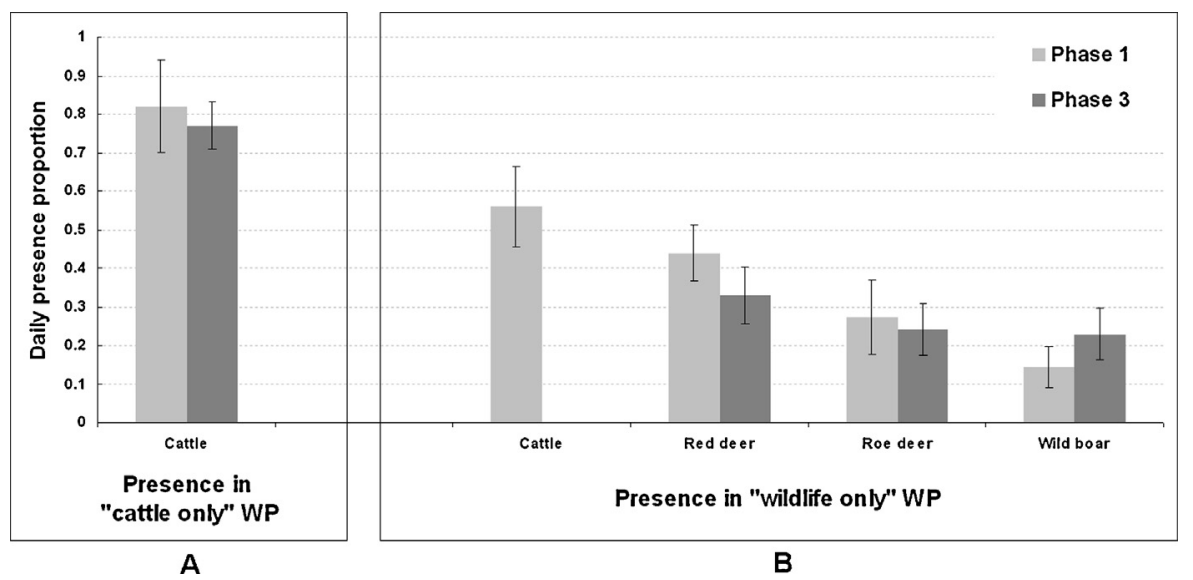

Fig. 5. (A) Daily presence of cattle in "cattle only" WP types, before (Phase 1) and after selectively fencing measures (Phase 3). (B) Daily presence of cattle and wild ungulates in WP selectively intended to wild ungulates. Bars refer to Phase 1 (previous to fencing) and Phase 2 (after selectively fencing the WP). Error bars are represented in $95 \% \mathrm{CI}$.

impossibility of farmers to freely trade and move cattle, which obligate them to rear and fatten calves at the farm. One could expect that the dominant effect in our study case of disease transmission is direct interaction between species rather than environmental contagion, which would still be occurring outside the WP. Nonetheless, in Mediterranean habitats from south central Spain, water is a limited resource. Vicente et al. (2007) described a positive association between wildlife aggregation at water and TB-like lesions in big game estates, suggesting that aggregation could drive the risk of $M$. bovis transmission. Therefore, WP could act as high risk areas of spatio-temporal aggregation, especially in summer time in farms. Such points are potential high risk areas for disease transmission, which would explain why our intervention, just starting the summer before the last reported TB testing, resulted in a marked reduction of TB incidence in the study farm. We did not detect any direct interaction between species in this study, and recent research in a number of farms from the study area have evidenced that indirect interactions which pose a spillback risk into cattle occurred more often during the dry season and would occur more frequently at water points, whereas no direct interaction have been observed (the authors, unpublished). Also, M. bovis has shown long survival times during high humidity conditions in sites with close climatological conditions to Ciudad Real (Duffield and Young, 1985; Tanner and Michel, 1999).

Technically, the gate we tested presented an inconvenience since it often rebounded against the post, which holds the delay catch system, due to the strength applied by the cow to open the gate, and we finally removed the posts. This may frighten some cows, especially at the beginning of Phase 2, and deter them from entering. In spite of that, cows successfully entered after a period of adaptation, and accompanying cows (those that did not operate the gate actively) also passed and were granted access to water. We recommend gates about $3 \mathrm{~m}$ in width, so once the cattle trigger the device they are almost all of the way inside the enclosure. In case the water source is scarce and cattle need to enter the enclosure to drink, alternating periods with the gate locked and unlocked, respectively (between Phase 2 and 3) may prevent from cows from not having access to water during the first days in Phase 3. This also provides comfort to the farmer, who might be concerned about the possibility that the cattle will not drink. In summary, this research provides empirical evidence that bump gates can be activated by cattle after a relatively short period of adaptation, for which we recommend

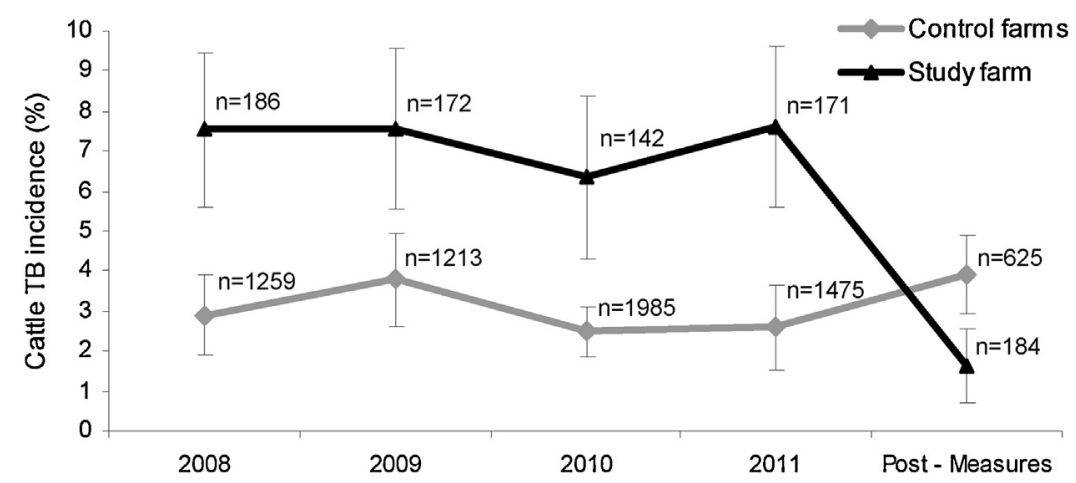

Fig. 6. Recent trends in cattle TB incidence (in \%) in two cattle extensive farm groups, the control farms (average incidence \pm SE) vs. the study farm. We display the number of tested cows for each year is included. Data on skin tests were provided by the sanitary authorities. 
following our "3 Phase" approach. For future experiences, the deployment of brushes as soon as possible around aggregation points should make cattle get rapidly used to them, improving the subsequent use of cattle-only gates. More research is needed in order to evaluate bump gate selectivity against wild ungulates since our study design did not allow us to fully evaluate this important aspect.

\subsection{Segregation of cattle and livestock at water points}

We completely segregated wild ungulates and cattle at WP during the critical dry season in a typical Mediterranean area. This was mainly achieved by impeding cattle from access to WP devoted to wild ungulates (Andrew et al., 1997). Apparently, the different species of wild ungulates that are present in the study area entered the enclosures by jumping (red and roe deer), using selective gates (roe deer), crossing the frames (roe deer) or undercrossing the fences (wild boar and carnivores). This may result in a first step to segregate game and farming activities (Vavra et al., 1999), without requiring huge linear fences to separate wildlife in large areas with the consequent problems involved (Boone and Hobbs, 2004; Hayward and Kerley, 2009).

One possibility would be implementing easily repositioned, temporary, or seasonal exclusion fencing (Vavra et al., 1999; Reidy et al., 2008), which may be useful for excluding ungulates, as was done by Geisser and Reyer (2004) to reduce crop damage by wild boar. Nonetheless, the complex aspect in our study resides in the fact that effective segregation of cattle and wildlife is required when both species share farm habitat (Gortazar et al., 2007), and already tested physical barriers that deter wild ungulates also impede passage of cattle. Our results will assist farmers in developing strategies for modifying farm practices to reduce potential for transmission of disease agents between wildlife and cattle by (i) impeding cattle access to standing water sources (e.g., waterholes, springs) commonly used by wildlife (Walter et al., 2012) and (ii) impeding wildlife access to water sources (e.g., water troughs) commonly used by cattle.

\section{Conclusions}

We demonstrate how simple, low-cost biosecurity measures can substantially reduce contact between cattle and wild ungulates. Our methods can be used in the context of integrated plans to mitigate pathogen transmission between cattle and wildlife, as Walter et al. (2012) recommends in Michigan, USA and can contribute to improved cost-effectiveness of such strategies. Where wildlife maintain disease (Naranjo et al., 2008), measures solely targeting biosecurity are unlikely to resolve the problem (Gortazar et al., 2011b). Decreasing the density and prevalence of TB in wildlife reservoirs (wild boar and red deer in Spain, which also may involve field vaccination) (Beltran-Beck et al., 2012; Boadella et al., 2012), and regulating management that convey risks (such as the supplemental feeding of big game, e.g. Carstensen and DonCarlos, 2011) must complement biosecurity programmes in farms in order to decrease TB transmission (Fine et al., 2011). The implementation of biosecurity programmes in extensive farms from Spain, especially in areas suffering from TB infection where a wildlife reservoir is present, is nowadays possible. Interview-based research, surveys and risk factor analyses (e.g. Rodriguez-Prieto et al., 2012; Vicente et al., 2007) may provide initial guidance for on-farm mitigation of disease transmission. Moreover, several other potentially water-borne infections may also benefit from improved biosecurity at WP.

Finally, concerning the generalization of our results to other situations, the wildlife/livestock interface presents distinct characteristics due to different species involved, landscape composition, and farming and wildlife management, and therefore exclusion measures performed on a given farm are dependent upon the respective country or region experiencing TB (or any other shared disease) in cattle. Nonetheless, selectively operated gates can be used under different situations and risk points in other contexts to impede the presence of animals in farms (incidental or animals attracted for various reasons, including food sources, shelter or water). More research is needed for segregating other livestock species from wild ungulates, such as small ruminants and free-roaming pigs, which is a challenge.

\section{Conflict of interest}

The authors declare no conflict of interest.

\section{Acknowledgements}

This study was funded by the research project AGL201020730-C02-01 (Ministerio de Ciencia e Innovacion) and PEII10-0262-7673 (JCCM). Jose Angel Barasona enjoyed scholarship of the JCCM. We thank the Agriculture department of the JCCM and its Delegation in Ciudad Real by providing data on hunting statistics and sanitary campaigns. We also thank Jose Luis Saez (Spanish Agriculture Ministry) for his valuable comments on the manuscript.

\section{References}

Andrew, N.G., Lesicka, L.M., Bleich, V.C., 1997. An improved fence design to protect water sources for native ungulates. Wild. Soc. Bull., 823-825. Aranaz, A., de Juan, L., Montero, N., Sanchez, C., Galka, M., Delso, C., Alvarez, J., Romero, B., Bezos, J., Vela, A.I., Briones, V., Mateos, A., Dominguez, L. 2004. Bovine tuberculosis (Mycobacterium bovis) in wildlife in Spain. J. Clin. Microbiol. 42, 2602-2608.

Beltran-Beck, B., Ballesteros, C., Vicente, J., de la Fuente, J., Gortazar, C., 2012. Progress in oral vaccination against tuberculosis in its main wildlife reservoir in Iberia, the Eurasian Wild Boar. Vet. Med. Int., ID978501.

Berentsen, A.R., Dunbar, M.R., Mclean, R.G., 2007. Research strategies to reduce bovine tuberculosis transmission from wildlife to cattle. Proc. Wild. Dam. Manage. Conf. 12, 232-239.

Boadella, M., Vicente, J., Ruiz-Fons, F., de la Fuente, J., Gortazar, C. 2012. Effects of culling Eurasian wild boar on the prevalence of Mycobacterium bovis and Aujeszky's disease virus. Prev. Vet. Med. 107, 214-221.

Böhm, M., Hutchings, M.R., White, P.C.L., 2009. Contact networks in a wildlife-livestock host community: identifying high-risk individuals in the transmission of bovine TB among badgers and cattle. PLoS One 4, e5016, http://dx.doi.org/10.1371/journal.pone.0005016.

Boone, R.B., Hobbs, N.T., 2004. Lines around fragments: effects of fencing on large herbivores. Afr. J. Rang. For. Sci. 21, 147-158.

Bugalho, M.N., Milne, J.A., 2003. The composition of the diet of red deer (Cervus elaphus) in a Mediterranean environment: a case of summer nutritional constraint? For. Ecol. Manage. 181, 23-29. 
Carstensen, M., DonCarlos, M.W., 2011. Preventing the establishment of a wildlife disease reservoir: a case study of bovine tuberculosis in wild deer in Minnesota, USA. Vet. Med. Int., ID413240.

Corner, L.A.L., 2006. The role of wild animal populations in the epidemiology of tuberculosis in domestic animals: How to assess the risk. Vet. Microb. 112, 303-312.

Delahay, R.J., Smith, G.C., Ward, A.I., Cheeseman, C.L., 2005. Options for the management of bovine tuberculosis transmission from badgers (Meles meles) to cattle: evidence from a long-term study. Mammal Study 30, 73-81.

Delibes-Mateos, M., Farfan, M.A., Olivero, J., Marquez, A.L., Vargas, J.M., 2009. Long-term changes in game species over a long period of transformation in the Iberian Mediterranean landscape. Environ. Manage. 43, 1256-1268.

Duffield, B., Young, D., 1985. Survival of Mycobacterium bovis in defined environmental conditions. Vet. Microb. 10, 193-197.

Fine, A.E., Bolin, C.A., Gardiner, J.C., Kaneene, J.B., 2011. A study of the persistence of Mycobacterium bovis in the environment under natural weather conditions in Michigan, USA. Vet. Med. Int., ID765430.

Garnett, B., Delahay, R., Roper, T., 2002. Use of cattle farm resources by badgers (Meles meles) and risk of bovine tuberculosis (Mycobacterium bovis) transmission to cattle. Proc. Roy. Soc. Lond. B. 269, 1487-1491.

Gehring, T.M., VerCauteren, K.C., Provost, M.L., Cellar, A.C., 2011. Utility of livestock-protection dogs for deterring wildlife from cattle farms. Wild. Res. 37, 715-721.

Geisser, H., Reyer, H.U., 2004. Efficacy of hunting, feeding, and fencing to reduce crop damage by wild boars. J. Wild. Manage. 68, 939-946.

Gilsdorf, J.M., Hygnstrom, S.E., VerCauteren, K.C., Blankenship, E.E., Engeman, R.M., 2004. Propane exploders and electronic guards were ineffective at reducing deer damage in cornfields. Wildl. Soc. Bull. 32 524-531.

Gortazar, C., Acevedo, P., Ruiz-Fons, F., Vicente, J., 2006. Disease risks and overabundance of game species. Eur. J. Wildl. Res. 52, 81-87.

Gortazar, C., Ferroglio, E., Hofle, U., Frolich, K., Vicente, J., 2007. Diseases shared between wildlife and livestock: a European perspective. Eur. J. Wild. Res. 53, 241-256.

Gortazar, C., Torres, M.J., Acevedo, P., Aznar, J., Negro, J.J., de la Fuente, J. Vicente, J., 2011a. Fine tuning the space, time, and host distribution of mycobacteria in wildlife. BMC Microbiol., 11-27.

Gortazar, C., Vicente, J., Boadella, M., Ballesteros, C., Galindo, R.C., Garrido, J., Aranaz, A., De la Fuente, J., 2011b. Progress in the control of bovine tuberculosis in Spanish wildlife. Vet. Microbiol. 151, 170-178.

Grandin, T., 1980. Observations of cattle behavior applied to the design of cattle-handling facilities. Appl. Animal Ethol. 6, 19-31.

Hayward, M.W., Kerley, G.I.H., 2009. Fencing for conservation: restriction of evolutionary potential or a riposte to threatening processes? Biol. Conserv. 142, 1-13.

http://www.delaval.es/en/-/Product-Information1/Animal-comfort-care/ Products/Body-care/Cow-brushes/DeLaval-swinging-cow-brush (accessed 15.12.12).

Hutchings, M., Harris, S., 1997. Effects of farm management practices on cattle grazing behaviour and the potential for transmission of bovine tuberculosis from badgers to cattle. Vet. J. 153, 149-162.

Hutchings, M., Harris, S., 1999. Quantifying the risks of TB infection to cattle posed by badger excreta. Epid. Inf. 122, 167-174.

Judge, J., McDonald, R.A., Walker, N., Delahay, R.J., 2011. Effectiveness of biosecurity measures in preventing badger visits to farm buildings. PLoS One 6, e28941.

Karhu, R.R., Anderson, S.H., 2006. The effect of high-tensile electric fence designs on big-game and livestock movements. Wild. Soc. Bull. 34, 293-299.

Kuiken, T., Leighton, F.A., Fouchier, R.A.M., LeDuc, J.W., Peiris, J.S.M., Schudel, A., Stohr, K., Osterhaus, A.D.M.E., 2005. Pathogen surveillance in animals. Science 309, 1680-1681.

Lavelle, M.J., Vercauteren, K.C., Hefley, T.J., Phillips, G.E., Hygnstrom, S.E., Long, D.B., Fischer, J.W., Swafford, S.R., Campbell, T.A., 2011. Evaluation of fences for containing feral swine under simulated depopulation conditions. J. Wild. Manage. 75, 1200-1208.

Lee, C., Henshall, J.M., Wark, T.J., Crossman, C.C., Reed, M.T., Brewer, H.G., O'Grady, J., Fisher, A.D., 2009. Associative learning by cattle to enable effective and ethical virtual fences. Appl. Anim. Behav. Sci. 119, 15-22.

Miller, R.A., Kaneene, J.B., Fitzgerald, S.D., Schmitt, S.M., 2003. Evaluation of the influence of supplemental feeding of white-tailed deer (Odocoileus virginianus) on the prevalence of bovine tuberculosis in the Michigan wild deer population. J. Wild. Dis. 39, 84-95.

Moran, J., 1993. Calf Rearing - A Guide to Rearing Calves in Australia. AgMedia. NSW Feedlot manual Feb (1997) NSW Agriculture.
Moreno, G., Pulido, F., 2008. The functioning, management and persis tence of dehesas. Adv. Agroforest. 6, 127-160.

Naranjo, V., Gortazar, C., Vicente, J., de la Fuente, J., 2008. Evidence of the role of European wild boar as a reservoir of Mycobacterium tuberculosis complex. Vet. Microbiol. 127, 1-9.

Olea, L., San Miguel-Ayanz, A., 2006. The Spanish dehesa. A traditional Mediterranean silvopastoral system linking production and nature conservation. Grassland Sci. Eur. 11, 3-13.

Palmer, M.V., Whipple, D.L., Waters, W.R., 2001. Experimental deer-to deer transmission of Mycobacterium bovis. Am. J. Vet. Res. 62, 692-696.

Palmer, M.V., Waters, W.R., Whipple, D.L., 2004. Shared feed as a means of deer-to-deer transmission of Mycobacterium bovis. J. Wild. Dis. 40 87-91.

Paterson, B., Morris, R., Weston, J., Cowan, P., 1995. Foraging and denning patterns of brushtail possums, and their possible relationship to contact with cattle and the transmission of bovine tuberculosis. N. Z. Vet J. 43, 281-288.

Phillips, C., 2002. Cattle Behaviour and Welfare. Wiley Online Library.

Phillips, C., Foster, C., Morris, P., Teverson, R., 2003. The transmission of Mycobacterium bovis infection to cattle. Res. Vet. Sci. 74, 1-15.

Phillips, G.E., Lavelle, M.J., Fischer, J.W., White, J.J., Wells, S.J., Vercauteren, K.C., 2012. A novel bipolar electric fence for excluding white-tailed deer from stored livestock feed. J. Anim. Sci. 90, 4090-4097.

Reidy, M.M., Campbell, T.A., Hewitt, D.G., 2008. Evaluation of electric fencing to inhibit feral pig movements. J. Wild. Manage. 72, 1012-1018.

Rodriguez-Prieto, V., Martinez-Lopez, B., Barasona, J.A., Acevedo, P. Romero, B., Rodriguez-Campos, S., Gortazar, C., Sanchez-Vizcaino, J.M., Vicente, J., 2012. A Bayesian approach to study the risk variables for tuberculosis occurrence in domestic and wild ungulates in South Central Spain. BMC Vet. Res. 8, 148.

Seward, N.W., Phillips, G.E., Duquette, J.F., Vercauteren, K.C., 2007. A frightening device for deterring deer use of cattle feeders. J. Wild. Manage. 71, 271-276.

Simonsen, H., 1979. Grooming behaviour of domestic cattle. Nord. Vet. Med. 31, 1.

Tanner, M., Michel, A.L., 1999. Investigation of the viability of M. bovis under different environmental conditions in the Kruger National Park. Onderstepoort J. Vet. Res. 3, 185-190.

Tolhurst, B.A., Delahay, R.J., Walker, N.J., Ward, A.I., Roper, T.J., 2009. Behaviour of badgers (Meles meles) in farm buildings: Opportunities for the transmission of Mycobacterium bovis to cattle? Appl. Anim. Behav. Sci. 117, 103-113.

Vavra, M., Willis, M.J., Sheehy, D.P., 1999. Livestock-big game relationships: conflicts and compatibilities, Grazing behavior of livestock and wildlife. Station. Bull. 70, 130-136.

VerCauteren, K.C., Gilsdorf, J.M., Hygnstrom, S.E., Fioranelli, P.B., Wilson, J.A., Barras, S., 2006a. Green and blue lasers are ineffective for dispersing deer at night. Wild. Soc. Bull. 34, 371-374.

VerCauteren, K.C., Lavelle, M.J., Hygnstrom, S., 2006b. Fences and deerdamage management: a review of designs and efficacy. Wild. Soc. Bull. 34, 191-200.

VerCauteren, K.C., Seward, N.W., Lavelle, M.J., Fischer, J.W., Phillips, G.E., 2007. A fence design for excluding elk without impeding other wildlife. Rang. Ecol. Manage. 60, 529-532.

VerCauteren, K.C., Lavelle, M.J., Phillips, G.E., 2008. Livestock protection dogs for deterring deer from cattle and feed. J. Wild. Manage. 72, 1443-1448.

VerCauteren, K.C., Seward, N.W., Lavelle, M.J., Fischer, J.W., Phillips, G.E., 2009. Deer guards and bump gates for excluding white-tailed deer from fenced resources. Hum. Wildlife Conflicts 3, 145-153.

Vercauteren, K.C., Vandeelen, T.R., Lavelle, M.J., Hall, W.H., 2010. Assessment of abilities of white-tailed deer to jump fences. J. Wild. Manage. 74, 1378-1381.

Vicente, J., Höfle, U., Garrido, J.M., Fernandez-De-Mera, I.G., Juste, R., Barral, M., Gortazar, C., 2005. Wild boar and red deer display high prevalences of tuberculosis-like lesions in Spain. Vet. Res. 37, 107119.

Vicente, J., Höfle, U., Garrido, J.M., Fernandez-de-Mera, I.G., Acevedo, P., Juste, R., Barral, M., Gortazar, C., 2007. Risk factors associated with the prevalence of tuberculosis-like lesions in fenced wild boar and red deer in south central Spain. Vet. Res. 38, 451-464.

Walter, W.D., Anderson, C.W., Smith, R., Vanderklok, M., Averill, J. VerCauteren, K.C., 2012. On-farm mitigation of transmission of tuberculosis from white-tailed deer to cattle: literature review and recommendations. Vet. Med. Int., 2012.

Wobeser, G.A., 2006. Essentials of Disease in Wild Animals, first ed. Blackwell Publishing Professional, Ames, IA. 